\title{
ERYTHRASMA - A CLINICAL AND A COMPARATIVE STUDY OF TOPICAL 2\% CLOTRIMAZOLE CREAM VS TOPICAL 2\% FUSIDIC ACID CREAM IN A SEMI-URBAN SETUP IN SOUTH INDIA
}

\author{
Prathyusha Prabhakar1, O. H. Hema², R. Sindhuja33, S. Murugan4, C. Vijayabhaskar 5 \\ 1 Junior Resident, Department of Dermatology, Chengalpattu Medical College. \\ 2 Professor and HOD, Department of Dermatology, Chengalpattu Medical College. \\ ${ }^{3}$ Assistant Professor, Department of Dermatology, Chengalpattu Medical College. \\ ${ }^{4}$ Assistant Professor, Department of Dermatology, Chengalpattu Medical College. \\ ${ }^{5}$ Associate Professor, Department of Dermatology, Chengalpattu Medical College.
}

\begin{tabular}{l}
\hline ABSTRACT \\
BACKGROUND \\
The knowledge of common dermatosis will be useful for adequate treatment and care of the patients. \\
AIM \\
The aim of the study is to determine the clinical pattern and comparison of topical $2 \%$ clotrimazole cream vs. $2 \%$ fusidic acid \\
cream in the treatment of Erythrasma in our medical college.
\end{tabular}
cream in the treatment of Erythrasma in our medical college.

\section{MATERIALS AND METHODS}

This was a hospital-based prospective study conducted for 1 year in our medical college situated in South India.

\section{RESULTS}

Groin was the most common site with itching and discoloration being predominant symptoms. It was most common among females. Comorbidities associated were Diabetes mellitus and Hypothyroidism; $\%$ fusidic acid cream was found to be superior to $2 \%$ clotrimazole in the treatment of Erythrasma.

\section{CONCLUSIONS}

Our data correlates with previous hospital-based studies of Erythrasma.

\section{KEYWORDS}

Wood's Lamp Reflection Score, Colour Intensity, Demarcation, Scaling.

HOW TO CITE THIS ARTICLE: Prabhakar P, Hema OH, Sindhuja R, et al. Erythrasma - a clinical and a comparative study of topical $2 \%$ clotrimazole cream vs topical 2\% fusidic acid cream in a semi-urban setup in South India. J. Evolution Med. Dent. Sci. 2016;5(75): 5523-5528, DOI: $10.14260 /$ jemds/2016/1248

\section{INTRODUCTION}

Erythrasma is a chronic superficial bacterial infection of the skin widely prevalent all over the world. It is common in tropical country like ours due to its climate. The causative agent is a gram positive aerobic diphtheroid called Corynebacterium minutissimum. Studies carried out by scientists regarding its microbiology, pathogenicity, biochemical characters and treatment has expanded our knowledge about the condition. These organisms normally contribute to cutaneous ecosystem. But when local or systemic devitalising factors are favourable, they behave as pathogens. Recently various studies have been conducted for therapeutic trials in erythrasma using topical imidazole group of antifungal or fusidic acid and oral macrolides.

Financial or Other, Competing Interest: None.

Submission 13-08-2016, Peer Review 07-09-2016,

Acceptance 12-09-2016, Published 16-09-2016.

Corresponding Author:

Prathyusha Prabhakar,

Usha Nivas, Main Road,

Chittur,

Palakkad-678101.

E-mail: prathyukiran09@gmail.com

DOI: $10.14260 /$ jemds/2016/1248

\section{MATERIALS AND METHODS}

50 cases of erythrasma were collected at random from the outpatients of Department of Dermatology in a medical college situated in South India over a period of 1 year from Jan. 2014 to Jan. 2015.

\section{Inclusion Criteria}

1. All patients of either sex within age between 18 and 60 years.

2. Patients with clinically confirmed diagnosis of erythrasma.

\section{Exclusion Criteria}

1. All patients of either sex less than 18 and more than 60 years.

2. Patients who were on treatment with systemic or topical antibiotics.

3. Patients who were on treatment with topical steroids.

4. Known hypersensitivity to any of the components of the study medications.

With informed consent, the cases were chosen for the study with the clinical diagnosis. Subsequently careful history was elicited with particular reference to the following: 
1. Sex of patient.

2. Symptoms related to predisposing conditions.

A detailed systemic and dermatological examination was done. Routine analysis of haemoglobin, urine, blood sugar, renal function tests, liver function tests were done. In appropriate cases, thyroid function tests and ELISA for HIV were done. The skin lesions were subjected to clinical examination and Wood's lamp visualisation. Culture was done in all patients. The site of the lesion was thoroughly cleaned and scraping was done.

The scales collected were inoculated using a sterile platinum loop into a medium containing Mueller-Hinton Agar enriched with blood. The inoculated plates were incubated at room temperature for 48 hours. After the confirmation of diagnosis, 50 patients were randomly divided into group $A$ and group B with 25 patients in each. Group A were treated with $2 \%$ clotrimazole cream and Group B with $2 \%$ fusidic acid cream for 2 weeks. Comparison of its efficacy was based on colour intensity, demarcation and Wood's lamp reflection score. Efficacy of treatment was assessed by the percentage in reduction of colour intensity, demarcation, scaling and Wood's lamp reflection score on $1^{\text {st }}$ day, $7^{\text {th }}$ day and $14^{\text {th }}$ day with physician's global assessment score.

- $\quad$ Grade 0 - worsened

- Grade 1 - nil improvement, 0-25\% reduction

- Grade 2 - mild improvement - 26-50\% reduction

- $\quad$ Grade 3 - moderate improvement - 50-75\% reduction

- Grade 4 - marked improvement - 76-100\% reduction

The response rate $\{\%$ reduction in colour intensity, scaling and demarcation $\}$ was assessed during every followup.

\section{Wood's Lamp Reflection Score}

- Score 2 - prominent red fluorescence

- $\quad$ Score 1 - mild red fluorescence

- $\quad$ Score 0 - no fluorescence

These score values are considered as follows:

- Complete response 0

- Partial response 0.5-1

- $\quad$ No response 1.5-2

\section{Statistical Analysis}

All variables were examined for outliers and non-normal distributions. The categorical variables were expressed as frequency and percentage. The quantity variables were expressed as mean and standard deviation. Descriptive statistics were used to evaluate baseline characteristics. The group comparison for the categorical variables were analysed using chi-square test and for quantity variables were analysed using Analysis of Variance (ANOVA) and Independent student ' $\mathrm{t}$ ' test (or Wilcoxon rank sum test when hypothesis of normality was rejected). P - Value of less than 0.05 was considered as statistically significant. The statistical analysis was carried out using statistical software SPSS 19.0.

\section{OBSERVATIONS}

\section{Sex Distribution}

Of the 50 cases of erythrasma studied, 22 were males and 28 were females. The incidence of males was $44 \%$ and females were $56 \%$.

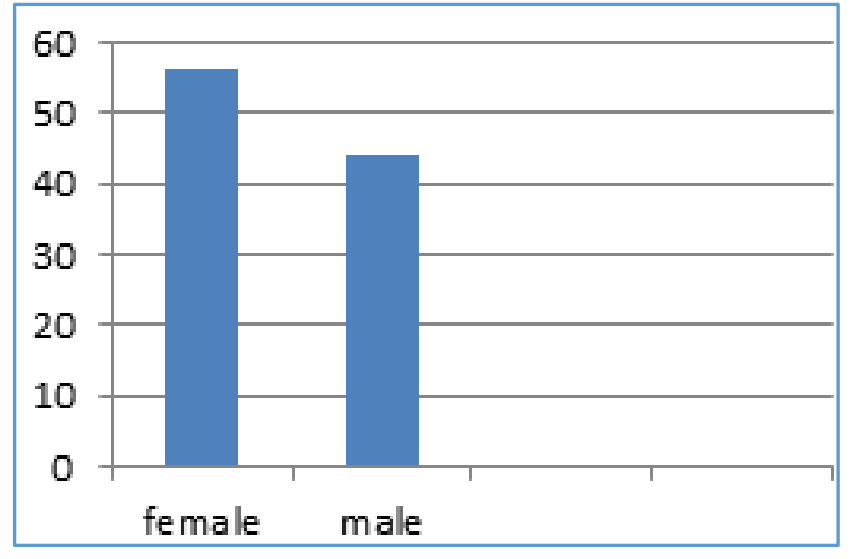

Age Distribution

Age distribution in the study varied from $18 \mathrm{yrs}$. to $60 \mathrm{yrs}$.

\begin{tabular}{|c|c|c|}
\hline Age in Years & No. of Cases & Percentage \\
\hline $20-30$ & 2 & 4 \\
\hline $30-40$ & 10 & 20 \\
\hline $40-50$ & 25 & 50 \\
\hline $50-60$ & 13 & 26 \\
\hline Total & $\mathbf{5 0}$ & $\mathbf{1 0 0}$ \\
\hline \multicolumn{3}{|c|}{ Table 1: Age Distribution } \\
\hline
\end{tabular}

$50 \%$ of the cases were in the age group of 40-50 years.

\section{GRAPH SHOWING AGE DISTRIBUTION}

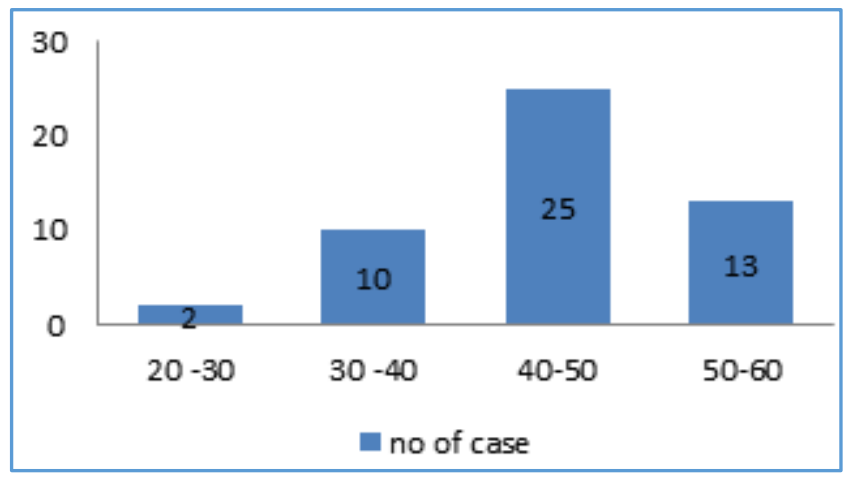

\section{Symptoms}

Itching and discoloration of the flexures were the predominant symptoms of erythrasma.

\begin{tabular}{|c|c|c|}
\hline Symptoms & No. of Cases & Percentage \\
\hline Itching & 10 & 20 \\
\hline Discoloration & 18 & 36 \\
\hline Both & 22 & 44 \\
\hline Total & $\mathbf{5 0}$ & $\mathbf{1 0 0}$ \\
\hline \multicolumn{3}{|c|}{ Table 2: Symptoms } \\
\hline
\end{tabular}


$44 \%$ of the cases presented with both itching and discoloration; $36 \%$ of the cases presented with cosmetic problem of discolouration; $22 \%$ of the cases presented with itching alone.

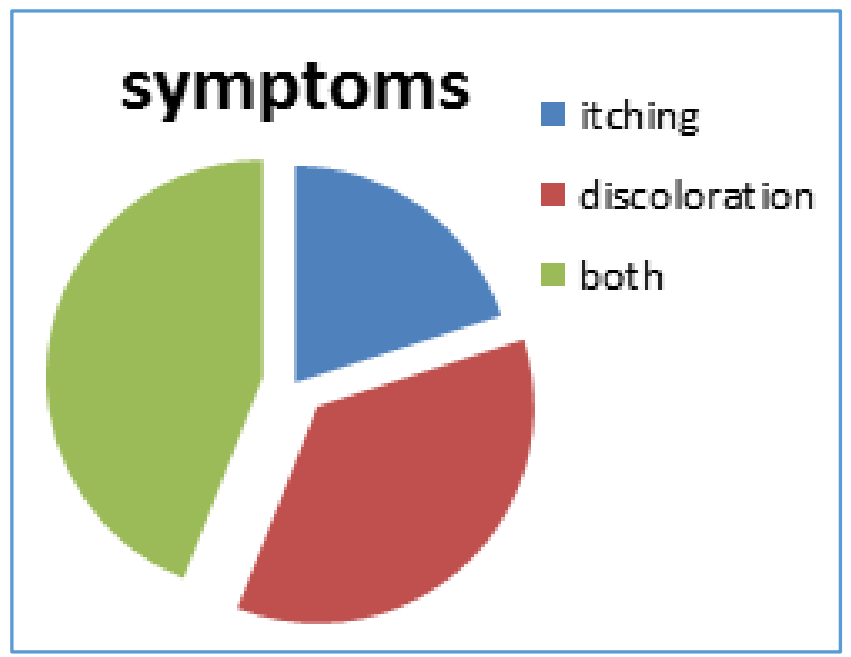

\section{Distribution of Lesions}

Most of the people had groin involvement [Fig. 1] followed by axilla [Fig. 2]. A few presented with inframammary area involvement [Fig. 3].

\begin{tabular}{|c|c|}
\hline Distribution & No. of Cases \\
\hline Axilla & 44 \\
\hline Groin & 46 \\
\hline Inframammary & 4 \\
\hline \multicolumn{2}{|c|}{ Table 3: Distribution of Lesions } \\
\hline
\end{tabular}

\section{GRAPH SHOWING DISTRIBUTION OF LESIONS}

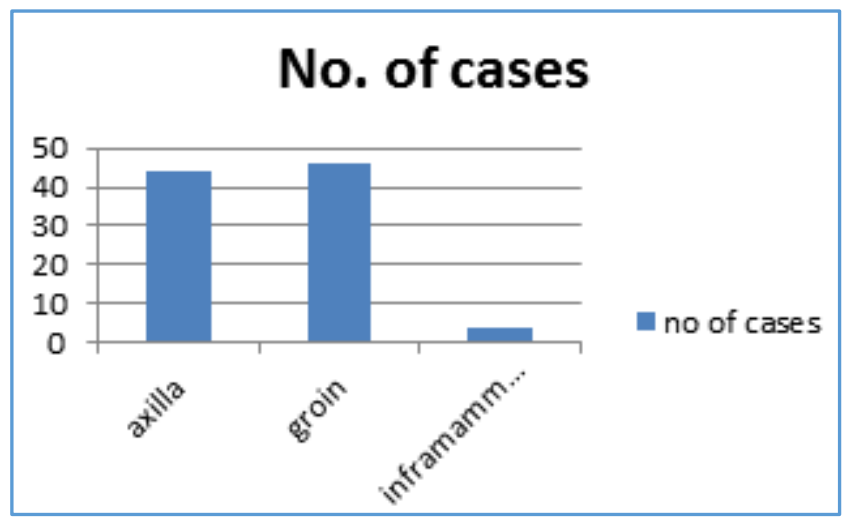

\section{Associated Corynebacterial Infections}

Keratolysis punctata [Fig. 4] was seen in 5 of the cases and trichomycosis axillaris [Fig. 5] in two of the patients.

\begin{tabular}{|c|c|c|}
\hline Infections & $\begin{array}{c}\text { No. of } \\
\text { Cases }\end{array}$ & Percentage \\
\hline Keratolysis punctata & 5 & 10 \\
\hline Trichomycosis axillaris & 2 & 4 \\
\hline \multicolumn{2}{|c|}{ Table 4: Associated Corynebacterial Infections } \\
\hline
\end{tabular}

GRAPH SHOWING NUMBER OF CASES ASSOCIATED WITH OTHER CORYNEBACTERIAL INFECTIONS

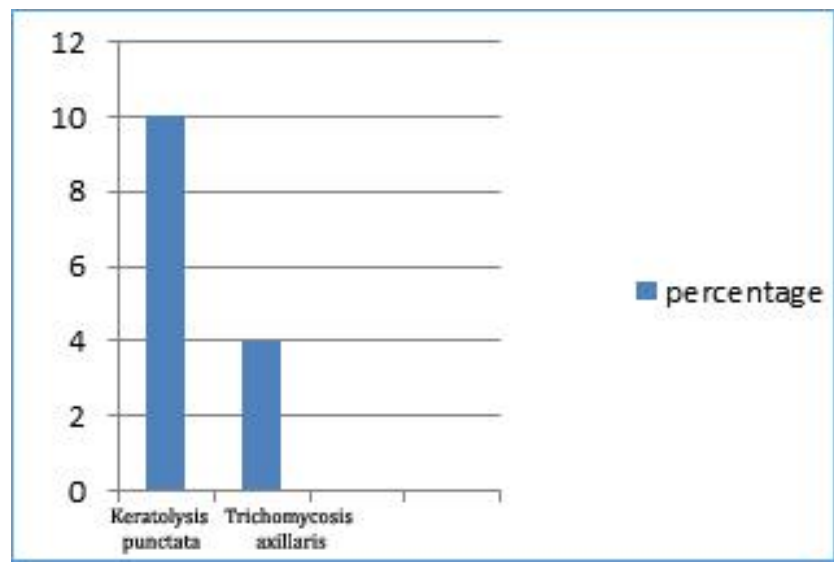

Associated Systemic Conditions

Among systemic conditions, obesity was associated with $60 \%$ of cases. Diabetes mellitus was associated with $50 \%$ of cases and hypothyroidism in $20 \%$ of cases.

\begin{tabular}{|c|c|c|}
\hline $\begin{array}{c}\text { Systemic } \\
\text { Diseases }\end{array}$ & No. of Cases & Percentage \\
\hline Obesity & 30 & 60 \\
\hline Diabetes mellitus & 25 & 50 \\
\hline Hypothyroidism & 10 & 20 \\
\hline \multicolumn{2}{|r|}{ Table 5: Associated Systemic Diseases } \\
\hline
\end{tabular}

GRAPH SHOWING PERCENTAGE OF CASES ASSOCIATED WITH SYSTEMIC DISEASES

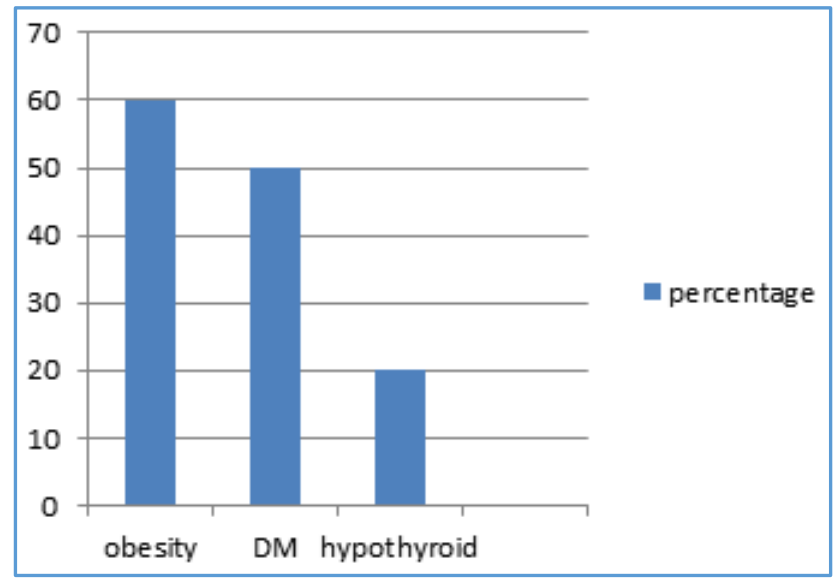

\section{Wood's Lamp Examination}

Portable Wood's lamp was used. The patient was advised to come without having bath. Coral red fluorescence (Fig. 6) was observed in all.

Culture

The scales were collected and inoculated into a medium of Mueller Hinton Agar enriched with blood. Small pale grey convex colonies (Fig. 7) appeared after 48 hours in only 4 cases out of 50 cases inoculated. 


\section{Treatment}

Among 50 cases with erythrasma, 25 patients treated with topical 2\% clotrimazole cream [Group A] and the remaining 25 patients with $2 \%$ fusidic acid cream [Group B]. In addition, they were given antihistamines in case if itching is present. These patients were compared on the basis of colour intensity, demarcation, scaling and Wood's lamp reflection scores on $1^{\text {st }}$, $7^{\text {th }}$ and $14^{\text {th }}$ day.

\begin{tabular}{|c|c|c|c|c|c|c|c|c|c|c|c|c|}
\hline \multirow{3}{*}{ Day } & \multicolumn{3}{|c|}{ Colour Intensity } & \multicolumn{3}{|c|}{ Demarcation } & \multicolumn{3}{|c|}{ Scaling } & \multicolumn{3}{|c|}{$\begin{array}{c}\text { Wood's Lamp } \\
\text { Reflection Score }\end{array}$} \\
\hline & \multicolumn{3}{|c|}{ Value } & \multicolumn{3}{|c|}{ Value } & \multicolumn{3}{|c|}{ Value } & \multicolumn{3}{|c|}{ Value } \\
\hline & $\mathbf{A}$ & B & $\mathbf{P}$ & $\mathbf{A}$ & B & $\mathbf{P}$ & $\mathbf{A}$ & B & $\mathbf{P}$ & $\mathbf{A}$ & B & $\mathbf{P}$ \\
\hline 7 & $\begin{array}{l}50.3 \pm \\
17.64\end{array}$ & $\begin{array}{c}64.85 \pm \\
18.35\end{array}$ & 0.064 & $\begin{array}{l}53.8 \pm \\
17.35\end{array}$ & $\begin{array}{c}66.53 \pm \\
22.54\end{array}$ & 0.034 & $\begin{array}{l}28.5 \pm \\
11.32\end{array}$ & $\begin{array}{l}38.5 \pm \\
12.51\end{array}$ & 0.046 & $\begin{array}{l}0.45 \pm \\
0.141\end{array}$ & $\begin{array}{l}0.03 \pm \\
0.032\end{array}$ & 0.001 \\
\hline 14 & $\begin{array}{l}65.5 \pm \\
21.21\end{array}$ & $\begin{array}{c}87.78 \pm \\
20.75\end{array}$ & 0.005 & $\begin{array}{l}76.5 \pm \\
12.54\end{array}$ & $\begin{array}{c}88.54 \pm \\
11.46\end{array}$ & 0.0009 & $\begin{array}{c}58.32 \pm \\
19.66\end{array}$ & $\begin{array}{c}78.25 \pm \\
15.62\end{array}$ & 0.002 & $\begin{array}{l}0.33 \pm \\
0.105\end{array}$ & $\begin{array}{l}0.01 \pm \\
0.016\end{array}$ & 0.0001 \\
\hline
\end{tabular}

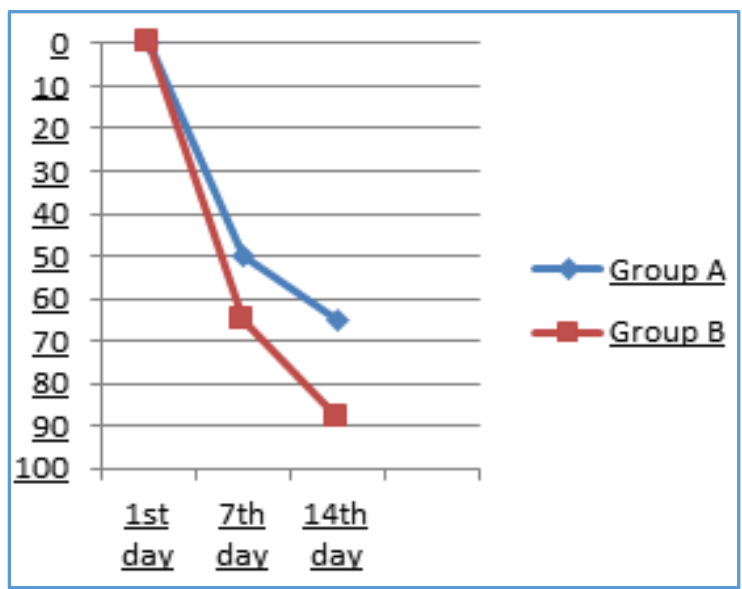

Colour Intensity

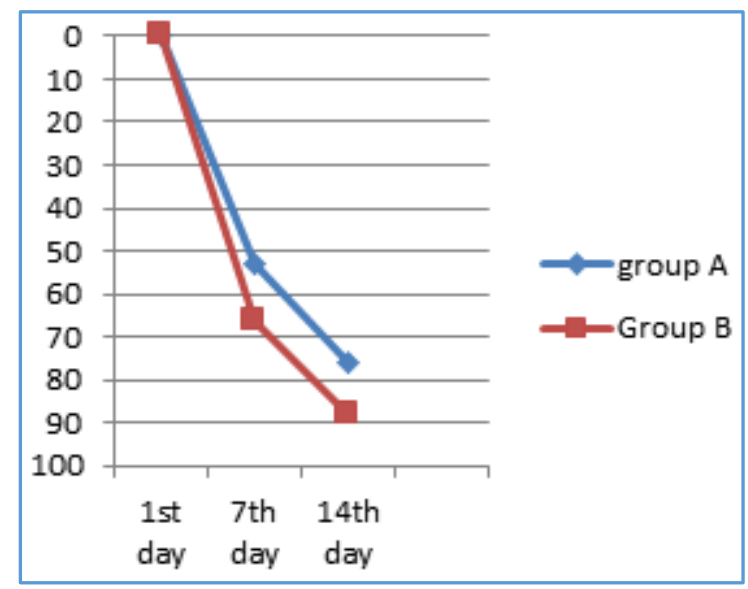

Demarcation

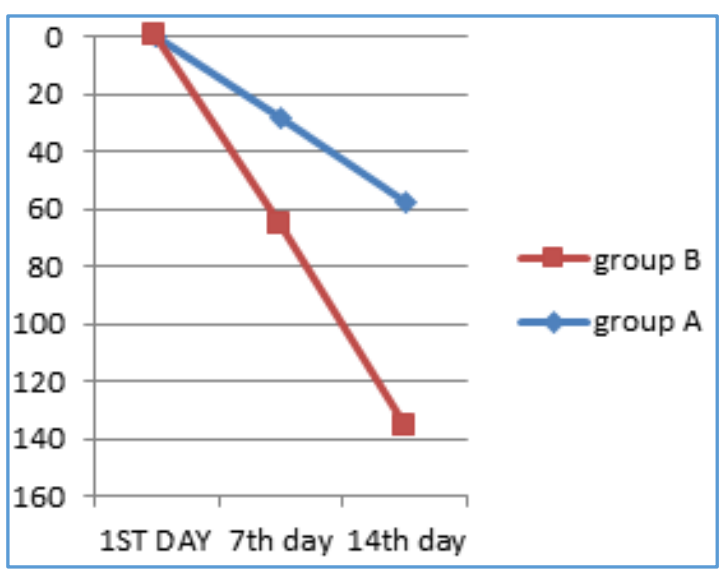

Scaling

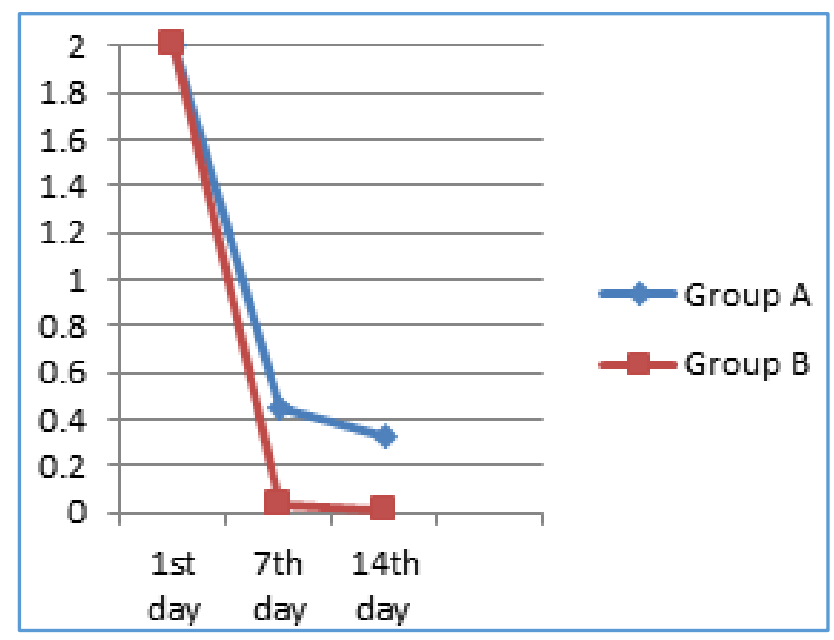

Wood's Lamp Reflection Score

In all parameters, Group B [2\% fusidic acid cream] showed better reduction compared to Group A [2\% clotrimazole cream]. So fusidic acid cream was found to be more effective by statistical analysis.

\section{RESULTS}

In this study, there were 28 female and 22 male patients and the incidence of erythrasma is more in females than in males. In literature erythrasma have equal sex incidence as reported by Gary L Darmstadt et al[1] and it is more common in men by Peter K Lee et al. ${ }^{[2]}$ In our study, this increased incidence may be due to the obesity commonly observed in females more than forty years; 25 patients $(50 \%)$ were between $40-50$ years of age; 48 cases (96\%) occurred in the 30-60 years' age group. The youngest age group observed was 21 years and oldest was 60 years. This correlates with the literature that incidence of erythrasma increase with age as reported by Gary L Darmstadt et al[1] and Laube S.[3] The prevalence of metabolic derangements like diabetes mellitus, obesity and hypothyroidism show an increase in middle age group which might be the reason for the occurrence of erythrasma in them. Also the presence of lipid in apocrine secretion after puberty may also influence the above finding.

22 patients ( $44 \%$ ) had itching and discoloration of flexures as their predominant complaint. Asymptomatic 18 cases (36\%), who reported only for the cosmetic inconvenience. In temperate climates, the erythrasma lesions were symptomless as reported by RJ Hay and BM Adrians, ${ }^{[4]}$ but in tropics irritation of lesions occur leading to scratching. The increased 
sweating and maceration in the flexures due to obesity might be the reason for itching in majority of cases. Groins were the most common site to be affected followed by axilla bilaterally and symmetrically. In literature also, erythrasma was described to occur most commonly in the groins by RJ Hay and BM Adrians.[4] All the intertriginous areas were affected. Shelley et al in 1982 described the coexistence of erythrasma with pitted keratolysis and trichomycosis axillaris.[5] The coexistence of the above infections with erythrasma indicates that common predisposing factors of moisture and obesity are involved in these conditions.

The literature reports of Haroon TS[6] and Scheinfeld NS[7] showed that the increased frequency of obesity and diabetes in the patients associated with erythrasma. This may be related to the high levels of cutaneous free glucose occurring in diabetes mellitus. Hypothyroidism and obesity may be the underlying cause in them which may predispose to erythrasma.

Wood's lamp showed coral red fluorescence. This test gave consistently positive results and the diagnosis of erythrasma was confirmed following which they were taken for therapeutic study.

Topical 2\% clotrimazole cream and 2\% fusidic acid cream showed greater reduction in colour, intensity and Wood's lamp reflection score in erythrasma during the first week. At the end of 2 nd week, $2 \%$ fusidic acid cream showed significant reduction in intensity, demarcation and Wood's lamp reflection score. In a double-blind, placebo-controlled study where oral erythromycin and topical $2 \%$ fusidic acid cream were used in 86 cases of erythrasma, it was found that the rate of complete response was $77 \%$ in the erythromycin group, $87 \%$ in the fusidic acid $2 \%$ cream group and $42 \%$ in the placebo group, and no statistically significant difference was found between these treatment modalities. [8] In another study, a twice-daily 14-day application of $2 \%$ fusidic acid cream had the success rate of up to $89 \%$ and no recurrence was seen in the 40th post-treatment week.[9] In the present study, the reduction in colour intensity from baseline to 2 weeks was significantly greater in $2 \%$ fusidic acid than $2 \%$ clotrimazole cream $\{89 \%$ vs. $76 \%\}$, demarcation $\{86 \%$ vs. $66 \%\}$ and scaling $\{78 \%$ vs. $58 \%\}$. Reduction was greater with $2 \%$ fusidic acid cream in these parameters. But the reduction in percentage of scaling was much lesser. The reduction in Wood's lamp reflection score was significantly greater in $2 \%$ fusidic acid cream than $2 \%$ clotrimazole cream. Wood's lamp reflection score was almost zero in $1^{\text {st }}$ week with $2 \%$ fusidic acid cream. In Oktay Vaci et al study, 2\% fusidic acid cream showed almost complete reduction in Wood's lamp reflection score.[10]

Response of treatment to $2 \%$ fusidic acid cream and $2 \%$ clotrimazole cream was moderate to marked. But marked response was seen in increased number in group of $2 \%$ fusidic acid cream compared to $2 \%$ clotrimazole cream. Few patients in $2 \%$ clotrimazole cream show mild improvement. Side effects like burning sensation; irritation or allergy contact dermatitis was not observed in any of the study groups. Compliance and tolerance were good in both groups.

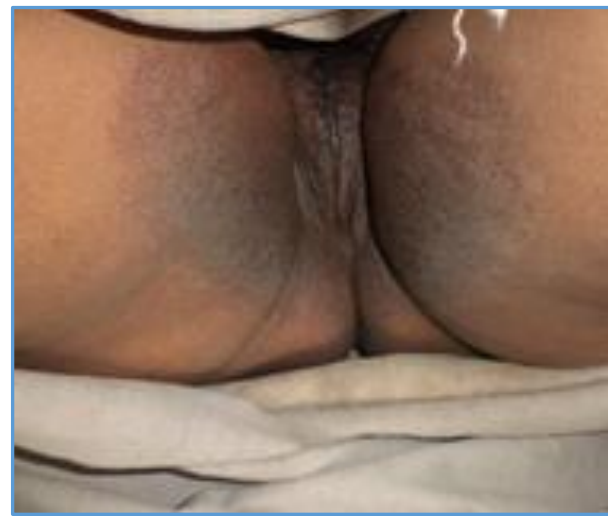

Fig. 1: Groin

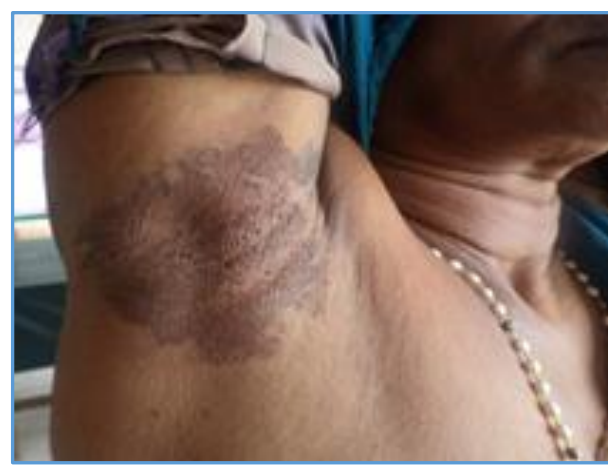

Fig. 2: Axilla

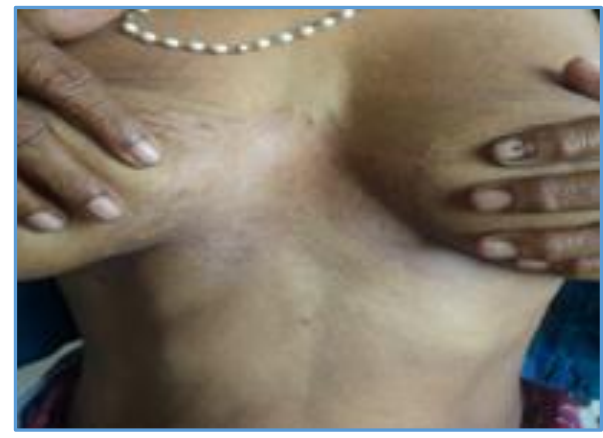

Fig. 3: Inframammary

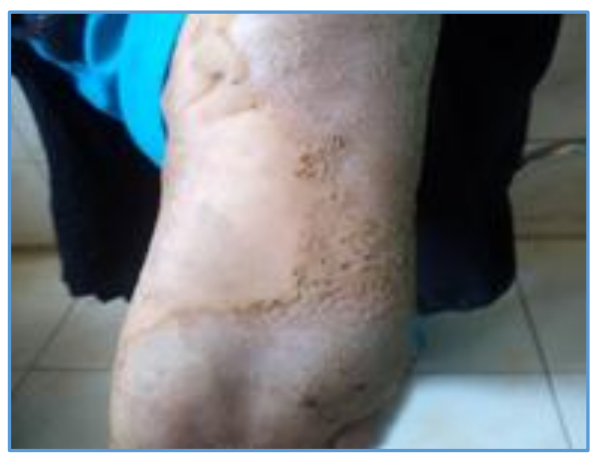

Fig. 4: Keratolysis Punctate 


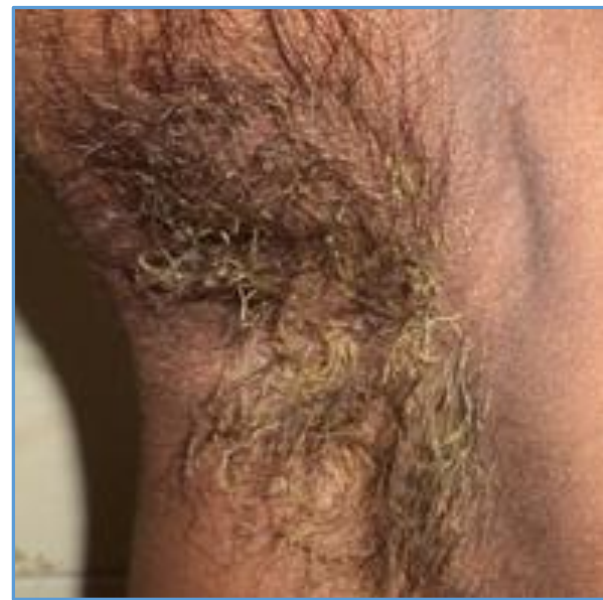

Fig. 6: Trichomycosis Axillaris

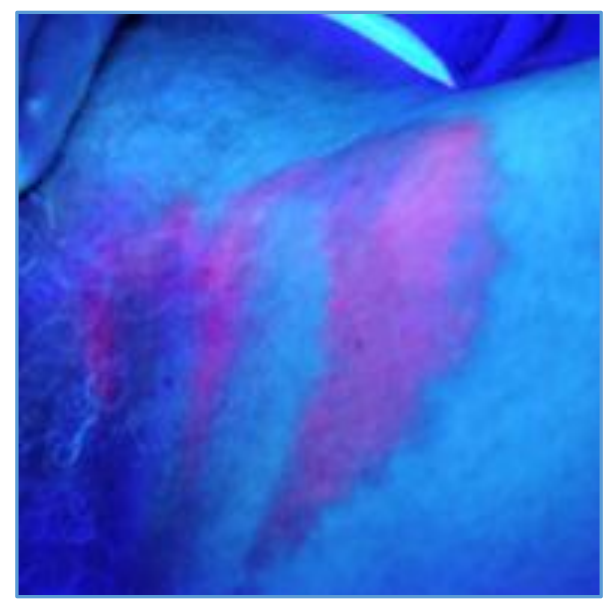

Fig. 7: Wood's Lamp Examination

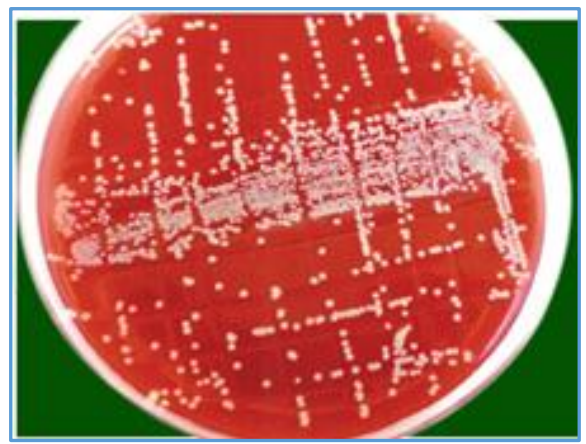

Fig. 8: Culture

\section{Group A - 2\% Clotrimazole Cream}

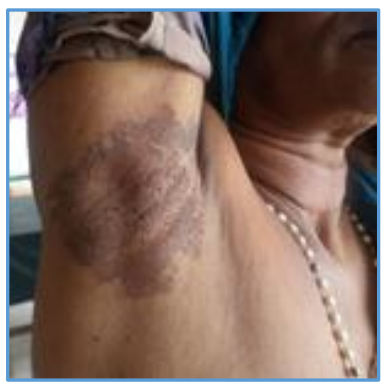

Before

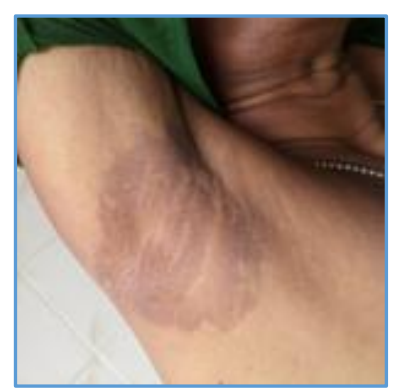

After
Group B - 2\% Fusidic Acid Cream

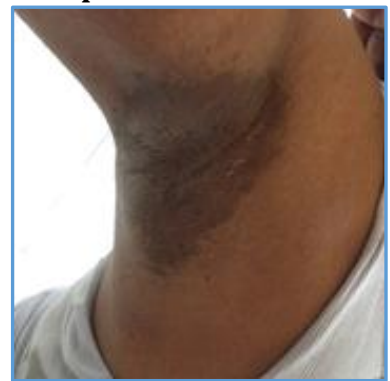

Before

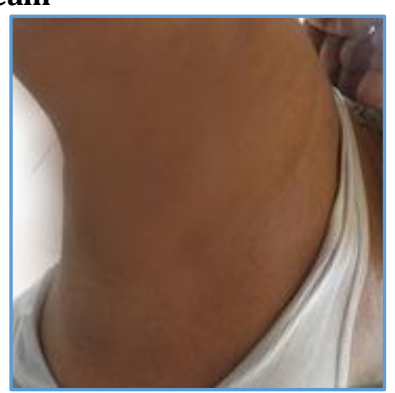

After

\section{CONCLUSIONS}

The following conclusions were drawn through the study regarding erythrasma: it is more common in females in the age group 40-50 years with discoloration and itching were the predominant symptoms. Groin is the most common site of involvement. Other corynebacterial infections like Keratolysis punctata and trichomycosis axillaris could be associated. Systemic disorders like obesity, diabetes mellitus and hypothyroidism could be associated. In general, topical $2 \%$ fusidic acid cream was found to be more effective than $2 \%$ clotrimazole cream in patients with erythrasma. It shows that antibacterial activity is more with $2 \%$ fusidic acid cream compared to $2 \%$ clotrimazole cream. Topical $2 \%$ clotrimazole cream is effective when there is associated fungal infection. Patients were taken for study after ruling out fungal infections and hence the decreased efficacy of $2 \%$ clotrimazole cream.

\section{REFERENCES}

1. Darmstadt GL, Galen WK, Fischer G. Bacterial infections. In: Schachner LA, Hansen RC, eds. Pediatric dermatology. $3^{\text {rd }}$ edn. London: Mosby 2003:1036.

2. Klee P, Zipolli MT, Weinberg AN, et al. Pyodermas, Chap :194. In: Irwin M, Freedberg, eds. Fitzpatrick's dermatology in general medicine. $6^{\text {th }}$ edn. Vol.2. New York: McGraw Hill 2003:1876.

3. Laube S. Skin infections and ageing. Ageing Res Rev 2004;3(1):69-89.

4. Hay RJ, Adrians BM. Bacterial infections. In: Burns T, Breathnach S, Cox N, et al. eds. Rook's textbook of dermatology. $7^{\text {th }}$ edn. Vol.2. Oxford: Blackwell Science 2004.

5. Shelley WB, Shelley ED. Coexistent erythrasma, trichomycosis axillaris and pitted keratolysis-an overlooked corynebacterial triad? J Am Acad Dermatol 1982;7(6):752-7.

6. Haroon TS. Diabetes and skin-a review. Scott Med J 1974;19(6):257-67.

7. Scheinfeld NS. Obesity and dermatology. Clin Dermatol 2004;22(4):303-9.

8. Hamann K, Thorn P. Systemic or local treatment of erythrasma? A comparison between erythromycin tablets and fucidin cream in general practice. Scand J Prim Health Care 1991;9(1):35-9.

9. MacMillan AL, Sarkany I. Specific topical therapy for erythrasma. Br J Dermatol 1970;82(5):507-9.

10. Avci O, Tanyildizi T, Kusku E. A comparison between the effectiveness of erythromycin, single-dose clarithromycin and topical fusidic acid in the treatment of erythrasma. J Dermatolog Treat 2013;24(1):70-4. 